\title{
ARSITEKTUR RUMAH ADAT SONAF BIKOMI-SANAK PADA MASYARAKAT MASLETE KABUPATEN TIMOR TENGAH UTARA NUSA TENGGARA TIMUR
}

\author{
Mario Yosef Kabosu ${ }^{1}$, Hermanu Joebagio ${ }^{1}$, Susanto ${ }^{1}$ \\ Diterima 14 Agustus 2018, Dipublikasikan 31 Oktober 2018 \\ CPenulis (2018)
}

\begin{abstract}
Sonaf Bikomi-Sanak is one form of cultural results that is owned by the Maslete community that has survived to this day. The architecture of the Sonaf Bikomi-Sanak traditional house is said to be one of the traditional architectures because its form is passed on from generation to generation, as the building's architectural form is very attached to the situation of the Maslete community and the surrounding environment. In the era of globalization marked by technological developments do not demand the Maslete people to change the shape of the building architecture of their traditional houses but instead the people still maintain the authenticity of the architecture of the traditional house of Sonaf Bikomi-Sanak. The method used in this study is qualitative descriptive. Data collection was obtained through interviews and observations..
\end{abstract}

\section{Keywords}

Traditional House, Sanak

\section{PENDAHULUAN}

Indonesia merupakan negara kepulauan yang terdiri dari berbagai suku bangsa dengan budaya yang memiliki ciri khasnya masing-masing. Hal ini menunjukkan masyarakat Indonesia merupakan masyarakat yang majemuk dan beraneka ragam budaya, sebagaimana tercermin dalam berbagai hasil kebudayaan. Keadaan ini sejalan dengan Koentjaraningrat (2005: 72) yang memberikan definisi kebudayaan sebagai seluruh sistem gagasan dan rasa, tindakan, serta karya yang dihasilkan manusia dalam hal kehidupan bermasyarakat yang dijadikan miliknya. Bertolak dari definisi yang dikemukakan oleh Koentjaraningrat, maka karya-karya budaya yang dihasilkan oleh manusia dan hingga kini masih bertahan di antaranya adalah arsitektur rumah adat, bahasa daerah, pakaian adat, dll.

Arsitektur rumah adat setiap daerah yang ada di Indonesia sangat beragam, sebab setiap suku memiliki rumah adatnya tersendiri dengan keunikan dan kekhasan yang dapat dijumpai pada bentuk dan jenis setiap rumah adat. Beragamnya jenis dan bentuk rumah adat yang ada, sejalan dengan Ariani (2014: 48) yang mengatakan bahwa di Indonesia jenis dan bentuk rumah adat sangat banyak jumlahnya dan beraneka ragam. Hampir setiap suku bangsa yang ada di Indonesia memiliki rumah adat sebagai lambang kebanggaan maupun identitas yang membedakan dengan suku bangsa lainnya. Begitu juga dengan masyarakat Maslete yang menjadikan rumah adat Sonaf Biko-Sanak sebagai rumah adat suku mereka, di mana selain

1 Program Pasca Sarjana Pend Sejarah, Fakultas Keguruan dan Ilmu Pendidikan, Universitas Sebelas Maret mariomars32@gmail.com 
sebagai lambang kebanggaan suku juga memiliki fungsi dan kaya akan nilai-nilai kearifan lokal yang mempersatukan masyarakatnya.

Arsitektur rumah adat Sonaf Biko-Sanak yang dimiliki masyarakat Maslete memiliki keunikan dan ciri khas bentuk bangunannya sesuai dengan keadaan lingkungan sekitarnya. Sejalan dengan itu, Hutari (2017: 62) mengatakan bahwa bentuk arsitektur sebuah bangunan tak bisa lepas dari situasi masyarakat pendukung dan keadaan lingkungannya. Hal ini menggambarkan bahwa keadaan lingkungan sekitar tempat rumah adat itu berada turut mempengaruhi bentuk sebuah arsitektur bangunan, dalam hal ini adalah bentuk bangunan rumah adat.

Rumah adat Sonaf Biko-Sanak merupakan salah satu warisan budaya yang secara turun temurun telah diwariskan oleh nenek moyang mereka kepada setiap generasinya. Sonaf BikoSanak selain sebagai tempat tinggal dalam melakukan segala aktivitas kehidupan sehari-hari, juga menjadi cerminan dalam perilaku bermasyarakat. Ada kekhawatiran yang sangat besar akan keberadaan rumah adat Sonaf Biko-Sanak yang menjadi salah satu kekayaan budaya bangsa sebagaimana seiring pesatnya perkembangan yang terjadi dalam ilmu pengetahuan dan teknologi dampaknya akan mengakibatkan kepunahan pada arsitektur rumah adat Sonaf BikoSanak. Pada akhirnya generasi selanjutnya yang ada di Maslete akan kehilangan jati dirinya selain itu juga akan kehilangan identitas arsitektur.

Permasalahan inilah yang mendorong dilakukan penelitian ini agar nantinya rumah adat Sonaf Biko-Sanak pada masyarakat Maslete tetap terjaga eksistensinya sehingga generasi selanjutnya tidak kehilangan jati diri mereka sebagai anggota suku Bikomi-Sanak. Hal tersebut sejalan dengan pernyataan Yudono dalam Rahmansha \& Rauf (2014: 57) bahwa semakin cepat dilakukan kajian untuk menggali kearifan arsitektur tradisional lokal semakin baik, sebelum para sesepuh bijak cerdik cendekia bidang budaya, sosiologi dan arsitektur tradisional terlanjur berpulang sehingga kita dapat merajut kembali local wisdom architecture tacit knowledge, yang sangat kita perlukan termasuk oleh generasi penerus.

\section{METODE}

Metode yang digunakan dalam kajian ini adalah metode deskriptif analisis dengan menggunakan pendekatan kualitatif. yang di gunakan dalam kajian ini adalah observasi dan wawancara. Observasi (pengamatan) secara langsung mengenai arsitektur rumah adat Sonaf Biko-Sanak, dan wawancara diperlukan untuk mendapatkan informasi dari para informan yang mengetahui secara mendalam mengenai arsitektur rumah adat Sonaf Biko-Sanak. Selain Teknik pengumpulan data melalui Observasi dan Wawancara ada juga studi pustaka di mana dilakukan agar mendapatkan data sekunder atau sumber-sumber tertulis.

\section{HASIL DAN PEMBAHASAN}

Liliweri (2014: 389) menjelaskan bahwa arsitektur Indonesia dipengaruhi oleh keanekaragaman budaya, sejarah dan geografi di Indonesia. Para penyerang, penjajah dan pedagang membawa perubahan kebudayaan yang sangat mempengaruhi gaya dan teknik konstruksi bangunan. Selanjutnya Liliweri juga menjelaskan bahwa sebagian besar arsitektur di Indonesia tersebar dalam penataan bangunan keagamaan, adat dan istana.

Ir. Hindro T. Soemardjan dalam makalahnya yang berjudul pendidikan arsitektur dan pembangunan nasional: sebuah pendekatan budaya memberikan definisi arsitektur sebagai cerminan kebudayaan. Arsitektur sebagai suatu karya kesenian hanya bisa tercapai dengan dukungan masyarakat yang luas. Untuk melahirkan karya arsitektur diperlukan selain arsitek, 
juga ahli-ahli teknik lainnya. Oleh karena itu, patutlah dikatakan bahwa arsitektur adalah manifestasi dari kebudayaan manusia. Atau dengan kata lain arsitektur selalu dipengaruhi oleh kebudayaan masyarakatnya (dalam Frick, 1996: 28). Sedangkan menurut Banchart C. L dan Jess Stein (dalam Hutari, 2017: 61) menjelaskan bahwa arsitektur adalah seni dalam mendirikan bangunan, di dalamnya termasuk segi perencanaan, konstruksi dan penyelesaian dekorasi.

Menurut Agus Dwi Hariyanto (2012: ix) arsitektur dipahami secara luas sebagai proses sekaligus produk pemenuhan kesejahteraan manusia melalui perancangan dan perencanaan. Selanjutnya menurut Sunarmi.,dkk (2007: 9) arsitektur dipahami sebagai fenomena kreatif manusia dalam memenuhi kebutuhan praktis untuk melindungi dirinya dari fenomena alam menunjukkan dinamika dari peradaban satu ke peradaban berikutnya.

Rumah merupakan bangunan standar dalam suatu sistem kebudayaan yang memberi perlindungan dan keselamatan karena merupakan benteng pertahanan. Menurut Waterson (1997: 89) mengatakan bahwa rumah merupakan bagian integral dari pandangan hidup masyarakatnya yang harus dipahami dalam konteks yang lebih luas, sehingga rumah juga merefleksikan kehidupan masyarakat yang bersangkutan.

Dalam sejarahnya rumah adat Sonaf Bikomi-Sanak didirikan untuk pertama kalinya pada tahun 1960-an sebagai simbol kesatuan totalitas dunia manusia dan alam supranatural tepatnya di Sasi, Kabupaten Timor Tengah Utara dan kemudian berpindah ke Maslete Kabupaten Timor Tengah Utara Nusa Tenggara Timur. Pemindahan lokasi rumah adat Sonaf Bikomi-Sanak dari Sasi ke Maslete dikarenakan alasan tertentu tetapi pada dasarnya hal tersebut atas kesepakatan anggota suku dan ketua suku Bikomi-Sanak.

Bentuk arsitektur rumah adat Sonaf Bikomi-Sanak secara garis besar pada bagian atapnya menyerupai perahu terbalik, dan ilalang yang telah kering sebagai penutup atapnya. Dasar untuk rumah adat Sonaf Bikomi-Sanak bukanlah keramik ataupun papan melainkan tanah. Bentuk bangunan rumah adat Sonaf Bikomi-Sanak memiliki makna sebagai mana menurut pandangan kehidupan masyarakat melambangkan alam semesta dan pemersatu suku. Sementara untuk inding yang menutupi rumah adat ini adalah papan. Baik itu ilalang, papan-papan yang digunakan untuk menutupi rumah adat serta kayu-kayu yang digunakan dalam pembuatan rumah adat Sonaf Bikomi-Sanak merupakan bahan-bahan yang terpilih berdasarkan hasil kesepakatan bersama sebelum mendirikan rumah adat ini. Sebagaimana diungkapkan oleh Djono, dkk (2012: 271) bahwa bangunan tradisi atau rumah adat merupakan salah satu wujud budaya yang bersifat konkret. Dalam konstruksinya setiap bagian atau ruang dalam rumah adat sarat dengan nilai dan norma yang berlaku pada masyarakat pemilik kebudayaan tersebut. Begitu juga dengan Sonaf Bikomi-Sanak, konstruksi bangunannya khas dengan fungsi setiap bagian yang berbeda satu sama lain mengandung unsur filosofis yang sarat akan nilai-nilai.

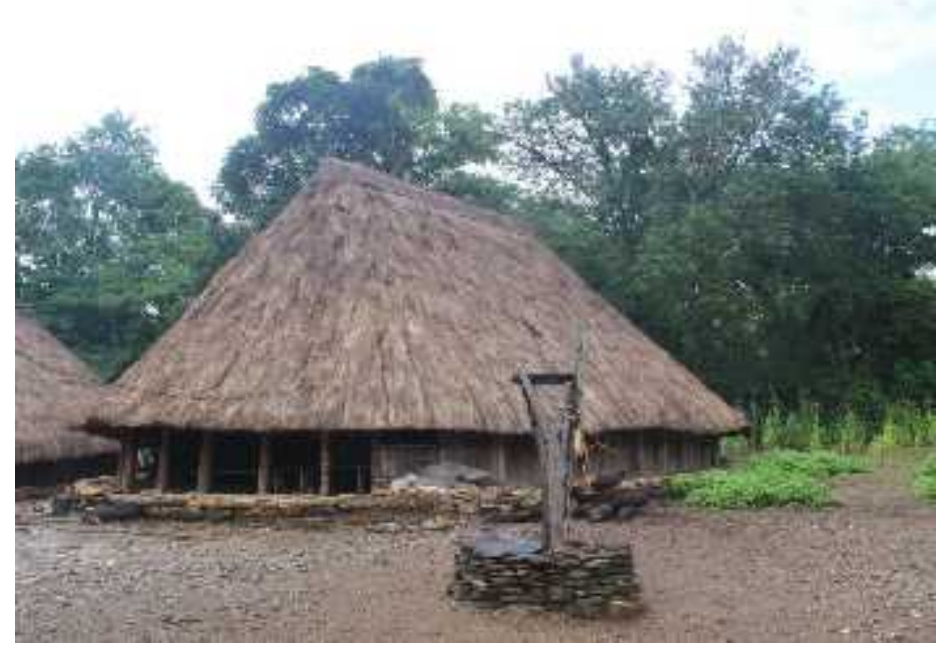

Gambar 1. Rumah Adat Sonaf Bikomi-Sanak ( Sumber: Dok. Pribadi tahun 2018) 
Setiap rumah adat yang dimiliki oleh suku bangsa yang ada di Indonesia tentunya menggunakan ragam hias sebagai pengindah arsitektur bangunan. Begitu juga pada arsitektur rumah adat Sonaf Bikomi-Sanak yang keindahan khas dari arsitektur rumah adat ini terwujud dalam bentuk ragam hiasnya. Untuk ragam hias yang ada pada setiap rumah adat tentunya berbeda-beda bentuk ragam hiasnya sesuai latar belakang masyarakat setempat. Arrafiani (2012: 48) mengatakan bahwa benda-benda alam yang ada di sekitar dapat diterjemahkan ke dalam bentuk ragam hias, antara lain tumbuhan, binatang, alam dan kepercayaan. Selanjutnya Arragiani menjelaskan bahwa wujud ragam hias pada bangunan tradisional memiliki arti dan maksud, antara lain: sebagai elemen untuk mempercantik atau menghiasi bangunan, sebagai alat komunikasi, dan sebagai ungkapan simbolis.
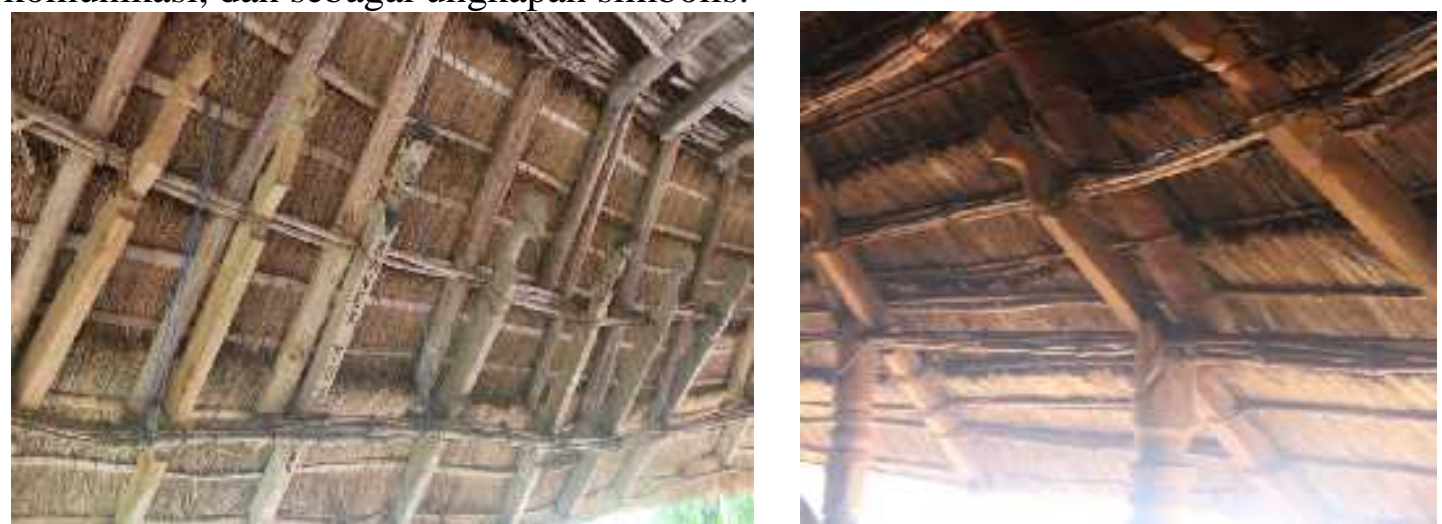

Gambar 2. Ragam hias yang menghiasi Sonaf Bikomi-Sanak (Sumber: Dok. Pribadi tahun 2018)

Pada umumnya untuk proses pembangunan rumah adat selalu disertai dengan upacara adat yang nantinya ditandai dengan penyembelihan hewan sebagai kurban. Tidak berbeda jauh dengan rumah adat lainnya, rumah adat Sonaf Bikomi-Sanakpun demikian sebagaimana proses pembuatan rumah adat disertai dengan upacara adat yang disesuaikan dengan tahapan dalam pembuatan rumah adat.

Tahapan kegiatan dalam proses pembangunan rumah adat Sonaf Bikomi-Sanak secara umum terbagi dalam tiga (3) tahapan, di antaranya tahap persiapan, tahap pelaksanaan dan tahap akhir. Ketika tahapan-tahapan dalam proses pembangunan rumah adat ini berlangsung semua suku-suku yang ada dalam rumah adat Sonaf Bikomi-Sanak akan terlibat di dalamnya.

\section{a. Tahap Persiapan}

Tahap persiapan ini biasanya terlebih dahulu diadakan pertemuan atau musyawarah adat yang dipimpin oleh seorang tua adat, sebagaimana dalam tahap awal ini dimulai dengan memohon kepada Tuhan serta para leluhur. Inti dari musyawarah ini adalah untuk membicarakan hal-hal yang berhubungan dengan pelaksanaan pembangunan rumah adat. Mereka yang hadir dalam musyawarah ini adalah kepala suku dan pemuka masyarakat. Keputusan yang diperoleh dari musyawarah ini adalah penentuan lokasi pembangunan rumah adat (sonaf Bikomi-Sanak), hari dan tanggal pembangunan dan pembagian bahan-bahan yang dibebankan kepada seluruh anggota suku Bikomi-Sanak untuk membawakannya.

Bahan-bahan yang disiapkan untuk kebutuhan pembangunan rumah adat sonaf BikomiSanak di antaranya adalah tiang-tiang yang menggunakan kayu putih yang berjumlah 6 sebagai tiang penopang 2 untuk tiang tertinggi dan 4 lagi untuk loteng. Untuk rangka kayu yang digunakan adalah kayu cemara, sebagaimana rangka rumah adat sonaf Bikomi-Sanak terdiri dari nonof, tunis, dan tfa. Ilalang yang digunakan untuk atap dan tali (nono) untuk mengikat 
ilalang dan kayu. Waktu yang dibutuhkan untuk mempersiapkan kebutuhan pembangunan rumah adat sonaf Bikomi-Sanak adalah 1 minggu.

Melihat bahan-bahan yang digunakan untuk pembangunan rumah adat sonaf Bikomi-Sanak sangatlah sederhana, hal ini menunjukkan bahwa masyarakat zaman dahulu sangat bergantung terhadap alam untuk memenuhi kebutuhan hidupnya.

\section{b. Tahap Pelaksanaan}

Pada umumnya masyarakat melakukan kegiatan yang berkaitan dengan adat selalu diawali dengan upacara seremonial adat, dengan tujuan agar segala sesuatu yang dilakukan dapat berjalan dengan baik sekaligus mendapat restu dari para leluhur. Karena bagi masyarakat Maslete keyakinan terhadap leluhur sebagai penjaga dan pemberi keselamatan akan peristiwa yang akan berlangsung.

Langkah-langkah pembuatan rumah adat sonaf Bikomi-Sanak dimulai dari fondasi rumah, pengukuran jarak tiang, penggalian lubang tiang induk dengan tiang pendek, pemasangan tiang induk dan tiang pendek, pemasangan balok loteng, pemasangan batang pinang, pinang yang dibelah, pemasangan dinding, pemasangan usuk-usuk, pengatapan. Proses pengatapan rumah adat memakan waktu 1 minggu.

Pada proses pengatapan rumah adat ini di isi dengan berbagai acara antara lain tarian gong dan meronggeng yang dilakukan dari pagi hingga pagi lagi dengan tujuan untuk menyemangati mereka yang bekerja. Dengan berakhirnya proses pengatapan rumah adat maka secara fisik telah selesai dan selanjutnya akan di lanjutkan dengan kegiatan lainnya yakni tahap terakhir tahap penutup.

\section{c. Tahap Akhir}

Setelah tahap persiapan dan tahap pelaksanaan selesai maka berikutnya adalah tahap akhir yang ditandai dengan proses pendinginan (hanik). Proses pendinginan merupakan tahapan akhir dari proses pendirian rumah adat sonaf Bikomi-Sanak. Bukan saja pada rumah adat sonaf Bikomi-Sanak melainkan berlaku juga pada rumah adat lainnya. Untuk acara pendinginan biasanya dilaksanakan upacara-upacara adat di antaranya penyembelihan hewan dan pengambilan air pemali dan kemudian di isi dengan tarian sepanjang malam sebagai ucapan syukur atas terselesaikannya proses pembangunan rumah adat sonaf Bikomi-Sanak.

Kehadiran rumah adat sonaf Bikomi-Sanak sangat berarti bagi kehidupan manusia terutama bagi suku Bikomi-Sanak sebab rumah adat ini bukanlah sekedar bangunan tua yang ada tetapi sangat berfungsi dalam keberlangsungan keseharian hidup. Untuk itu sangat penting mengetahui fungsi dari rumah adat itu sendiri di antaranya yakni sebagai tempat tinggal, sebagai tempat penyimpanan benda-benda kuno sebagai warisan dari nenek moyang, sebagai tempat untuk bermusyawarah, dan sebagai pemersatu suku-suku yang ada.

\section{SIMPULAN}

Rumah adat sebagai salah satu warisan budaya yang menjadi identitas kita seharusnya keberadaannya tetaplah terjaga, khususnya rumah adat sonaf Bikomi-Sanak. Karena perubahan zaman yang terjadi hingga saat ini menjadi sebuah ketakutan yang nantinya akan berdampak bagi arsitektur rumah adat itu sendiri maupun bagi generasi penerus sebagai pemilik dan pemakai rumah adat ini. Arsitektur rumah adat sonaf Bikomi-Sanak seharusnya tetap terjaga 
orisinalitasnya agar tetap menjadi ciri khas dan penanda bagi masyarakat Maslete Kabupaten Timor Tengah Utara Provinsi Nusa Tenggara Timur.

Bentuk arsitektur, proses pembuatan atau pendirian rumah adat serta fungsi rumah adat seharusnya di perkenalkan bahkan seharusnya diwajibkan bagi generasi muda untuk mengetahuinya, sehingga nantinya generasi muda tidak menjadi orang asing yang berada dalam wilayah tersebut dan tidak memandang rumah adat sonaf Bikomi-Sanak sebagai bangunan tua yang nampak tanpa memiliki fungsi karena telah kalah zaman, tetapi mereka seharusnya merasa bangga akan hasil kebudayaan yang telah di miliki secara turun-temurun di wariskan ke generasi selanjutnya sehingga harus tetap terjaga dan terawat. Generasi penerus yang nantinya mewarisi rumah adat sonaf Bikomi-Sanak seharusnya menjaga eksistensi rumah adat ini dan tetap menjadikan rumah adat ini sebagai salah satu warisan budaya yang seharusnya tetap terjaga karena sarat akan nilai-nilai luhur..

\section{DAFTAR PUSTAKA}

Ariani, Luh Ni. (2014). Rumah Adat Suku Lamaholot Korke (Bentuk dan Fungsi). Dalam Jurnal Penelitian Sejarah dan Nilai Tradisional, 21(1): 47-56.

Arrafiani. (2012). Rumah Etnik Bali. Jakarta: Griya Kreasi.

Djono., Utomo Tri Prasetyo., \& Subiyantoro Slamet. (2012). Nilai Kearifan Lokal Rumah Tradisional Jawa. Dalam Jurnal Humaniora, 24(3): 269-278.

Frick, Heinz. (1996). Arsitektur dan Lingkungan. Yogyakarta: Kanisius.

Hariyanto, A. Dwi. (2012). Kumpulan Makala seminar Nasional Menuju Arsitektur BerEmpati. Surabaya: jurusan Arsitektur Fakultas Teknik Sipil dan Perencanaan Universitas Kristen Petra.

Hutari, Fandy. (2017). Hiburan Masa Lalu dan Tradisional Lokal: Kumpulan Esai Seni, Budaya dan Sejarah Indonesia. Yogyakarta: INSISTPress.

Koentjaraningrat. (2005). Pengantar Antropologi I. Jakarta: PT Rineka Cipta.

Liliweri, Alo. (2014). Pengantar Studi Kebudayaan. Bandung: Nusa Media.

Rahmansah \& Rauf Bakhrani. (2014). Arsitektur Tradisional Bugis Makassar (Survei pada Atap Bangunan Kantor di Kota Makassar). Dalam Jurnal Forum Bangunan, 12(2): 56-63.

Sunarmi., Guntur., \& Utomu, Tri Prasetyo. (2007). Arsitektur \& Interior Nusantara Seri jawa. Surakarta: Institut Seni Indonesia (ISI) Surakarta \& UNS Prees Surakarta.

Waterson, Roxana. (1997). Living House, An Anthropology of Architecture in South-East Asia. Singapura: Oxford University Perss. 